\title{
Port connectivity indices: an application to European RoRo shipping
}

\author{
Peter W. de Langen ${ }^{1 *}$, Maximiliano Udenio ${ }^{1}$, Jan C. Fransoo ${ }^{1}$ and Reima Helminen ${ }^{2}$
}

\author{
${ }^{*}$ Correspondence: \\ p.w.d.langen@tue.nl \\ ${ }^{1}$ School of Industrial Engineering, \\ Eindhoven University of \\ Technology, Eindhoven, \\ Netherlands \\ Full list of author information is \\ available at the end of the article
}

\begin{abstract}
In recent years, there has been significant interest in the development of connectivity indicators for ports. For short sea shipping, especially in Europe, Roll-on Roll-off (RoRo) shipping is almost equally important as container shipping. In contrast with container shipping, RoRo shipments are primarily direct, thus the measurement of its connectivity requires a different methodology. In this paper, we present a methodology for measuring the RoRo connectivity of ports and illustrate its use through an application to European RoRo shipping. We apply the methodology on data collected from 23 different RoRo shipping service providers concerning 620 unique routes connecting 148 ports. We characterize the connectivity of the ports in our sample and analyze the results. We show that in terms of RoRo connectivity, neither the number of links nor the link quality (frequency, number of competing providers, minimum number of indirect stops) strictly dominate the results of our proposed indicator. The highest ranking ports combine link quality and number. Finally, we highlight promising areas for future research based on the insights obtained.
\end{abstract}

Keywords: Maritime connectivity, RoRo, European port network

\section{Introduction}

Maritime transport is crucial for trade. Lloyd's List Intelligence 2009, states that $75 \%$ of international cargo flows in terms of volumes ( $59 \%$ in terms of value) is seaborne. Transport policies, especially in Europe, support the use of maritime transport as the most economical and environmentally friendly transport modes; relevant EU initiatives include TEN-T, Motorways of the Sea, and Marco Polo I and II (see European Commission 2014). Future growth in maritime shipping is expected in all relevant forecasts (De Langen et al. (2012), UNCTAD 2014).

Given these policy initiatives, policymakers are interested in measures to track the quality of shipping networks over time. One of such measures is port connectivity. Connectivity is also a relevant performance indicator for port authorities (de Langen et al. 2007). Ports create value by connecting firms and consumers in the hinterland of a port with overseas markets and products. The better the connectivity of a port, the more value it creates for its users. Various ports highlight connectivity as an important selling point, particularly in container shipping (e.g., Port of Antwerp 2014). Recent initiatives by the European Sea Ports Organization (2010) aim to establish port connectivity indicators. Furthermore, port connectivity is clearly relevant for port users: a better connectivity means better access to overseas markets for imports and exports.

(c) 2016 The Author(s). Open Access This article is distributed under the terms of the Creative Commons Attribution 4.0 International License (http://creativecommons.org/licenses/by/4.0/), which permits unrestricted use, distribution, and reproduction in any medium, provided you give appropriate credit to the original author(s) and the source, provide a link to the Creative Commons license, and indicate if changes were made. 
The value of connectivity is straightforward for scheduled maritime services (shipping services operated according to a schedule). The higher the connectivity of a port, the more options for shippers and consignees to receive and send goods to/from overseas destinations. For unscheduled services (often termed tramp shipping, most bulk flows are unscheduled), the value of connectivity is not straightforward; shippers generally have large volumes and charter and fill complete ships and thus do not depend on predetermined routes and networks. While most liquid and dry bulk flows are not scheduled, most general cargo flows rely on the scheduled networks of container and Roll-on Roll-off (RoRo) shipping companies.

Various connectivity indicators have been developed exclusively dealing with container shipping networks ${ }^{1}$. In this paper, we develop a connectivity indicator for RoRo shipping and illustrate its use using data of 23 shipping companies operating in 148 European RoRo ports. RoRo is especially relevant in Europe, where over $65 \%$ of the total RoRo fleet by vessel capacity operates (MDS Transmodal 2013). For intra-European maritime transport, RoRo volumes in 2013, the last year for which statistics are available (see Eurostat 2015), were approximately 235 million Ton. This is comparable to containerized volumes (250 million ton, according to the same source). For a substantial number of countries, including France, the UK and most Baltic countries RoRo is more important for short sea shipping than container transport.

The rest of this paper is structured as follows. We present a short review of previous literature on connectivity indicators in Section 'Literature on connectivity in maritime transport'. Following this, we develop our RoRo connectivity indicator in Section 'A methodology to calculate a port's RoRo connectivity'. Section 'Empirical implementation: European RoRo shipping' presents the results based upon flows from EU core ports (as identified by the European Commission 2015a) with substantial RoRo volumes and their destinations. We conclude in Section 'Conclusions' by discussing the insights and future research directions.

\section{Literature on connectivity in maritime transport}

Port connectivity is regarded as the accessibility to scheduled maritime services in a port of observation ${ }^{2}$ (Pitoski et al. 2015). Port connectivity may be defined as an indicator of how well a port connects to other ports in a maritime network. In this view, the observation is limited to maritime links. In a second view, port connectivity may be defined more broadly, including all hinterland links of the transportation network. In this paper we focus on the maritime network.

Several studies have demonstrated the influence of maritime connectivity on trade costs, at a regional level (e.g., Wilmsmeier and Hoffmann 2008), and in a recent publication by the World Bank (Arvis et al. 2013) also at the global level. The majority of these studies use the Liner Shipping Connectivity Index (LSCI, Wilmsmeier and Hoffmann 2008), developed under the umbrella of the United Nations Conference on Trade and Development (UNCTAD). This index is the normalized average of five components that reflect the availability of container services to/from the assessed country:

1. the number of container ships on the liner services from and to country's ports,

2. the TEU carrying capacity of these ships, 
3. maximum vessel size,

4. the number of services,

5. the number of companies that deploy container ships on services from and to a country's ports.

Recently, several connectivity indices that build upon the LSCI have been developed for maritime container connectivity. Bartholdi et al. (2014) use LSCI's components to develop a container connectivity indicator at the port level. Bang et al. (2014) add information on ship size and number of competing shipping lines per string (whereas LSCI 'just' uses the number of shipping lines that provide services to/from a country, regardless of the trade). Jiang et al. (2015) add a method to include indirect connectivity through transshipment of containers in intermediate ports. These additions clearly show the interest in further advancing maritime connectivity indicators. However, these additions continue to focus on container shipping networks, which cannot be directly applied to RoRo transport. We expand the application of connectivity indicators to RoRo transport.

\section{A methodology to calculate a port's RoRo connectivity}

In this section, we develop a method to calculate a port's RoRo connectivity. Two questions are central. First, what components are used to calculate RoRo connectivity? Second, how is an indicator calculated from these components. Before we discuss these issues, we describe four general characteristics of RoRo transport that are relevant for these two questions.

First, RoRo shipping can be broadly divided in short sea services for passenger cars and trucks, and deep sea services for new cars (and trucks). The latter type of services is not included in our RoRo connectivity indicator, as they cannot be used for individual cars/trucks ${ }^{3}$.

Second, unlike other ships handled in ports, RoRo services often carry both passenger cars and freight trucks. The share of both changes according to the day of the week as well as the season. For instance, fresh produce often use RoRo services and are highly seasonal. For this reason, the ship capacity (in RoRo shipping generally expressed in lane-meters) cannot be attributed specifically to either cars or trucks.

Third, RoRo services generally cover relatively short distances. Many RoRo services operate due to the absence of a fixed link (for example the services between Algeciras and Tanger). Other services are in competition with road transport (for instance Barcelona to Livorno). Distances are generally limited (typically between 3 to $5000 \mathrm{~km}$ ) because over longer distances container transport becomes more cost-effective. The relatively long RoRo services are mostly used by unaccompanied trailers (no driver onboard).

Fourth, in contrast with the container market, there is very limited transshipment in RoRo networks. This is partly explained by the short distances and high time sensitivity of freight on board RoRo vessels. Given this characteristic, indirect connections, that are very relevant in container transport, are not relevant in RoRo and consequently not taken into account in the connectivity indicator.

\section{Potential components}

A review study of Pitoski et al. (2015) demonstrates that the following components were used in previously developed maritime connectivity indicators: 
- Vessel capacities (incl. maximum vessel size).

- Service frequency (port calls).

- Number of vessels deployed on services.

- Number of liner services / directly connected ports.

- Number of service providers.

- Transit time.

- Number of transshipments necessary for country-to-country trade.

In addition to these potential components, we identify one other potential component: distance. Various studies show that distance is strongly related with maritime freight rates (Wilmsmeier and Notteboom 2011) Nevertheless, the variable was never included directly into a maritime connectivity indicator ${ }^{4}$.

As discussed in more detail in Pitoski et al. (2015), the choice of components in the various connectivity indicators is based on an intuitive logic. All components are assumed to affect 'generalized transport costs' for port users. Some components are considered to be proxies for costs (vessel size and the number of service providers), other components are associated with the number and quality of links (e.g., the number of ports that are directly served, and the frequency and transit time of these services).

Table 1 lists all potential indicators, summarizes the theoretical arguments for including them in a RoRo connectivity indicator and presents the extent to which they are publicly available.

In conclusion, based on the analysis provided in Table 1, we argue that the following components are relevant for a RoRo connectivity indicator ${ }^{5}$ :

1. Number of RoRo destinations (+).

2. Service frequencies ${ }^{6}(+)$.

3. Number of service providers ${ }^{7}(+)$.

4. Minimum ${ }^{8}$ number of intermediate stops (-). A reduction of the number of intermediate stops will reduce transit times without a need to increase the service speed.

Figure 1 shows a stylized sketch of the application of these four components to an arbitrary port.

The aim of the method is to develop a 'connectivity score' of a particular port. Like LSCI, the scores of different ports (for LSCI: countries) can be compared. In addition, and more importantly, the connectivity score of a port can be monitored over time. We propose a method where the connectivity of a port is the sum of the 'link qualities' of all it's connections based on the 3 attributes of the links (attributes two, three and four in Fig. 1).

\section{The calculation method}

This section details how the connectivity indicator is calculated based on these components. Four questions are addressed:

1. What is the relative importance of the four components?

2. Is a linear effect of the value of the components on connectivity applied or not?

3. Does the method attribute different weights to different links?

4. Does the method differentiate the importance of the destination ports? 
Table 1 Components relevant in scope of RoRo maritime connectivity and data availability

\begin{tabular}{|c|c|c|c|}
\hline Components & Main references & Relevance for RoRo (theoretical) & $\begin{array}{l}\text { Data availability for } \\
\text { RoRo (empirical) }\end{array}$ \\
\hline Vessel capacities & $\begin{array}{l}\text { Jiang et al. (2015), UNCTAD's } \\
\text { LSCl, Wang and Cullinane } \\
\text { (2008). }\end{array}$ & $\begin{array}{l}\text { Not straightforward. Capacity is not a good proxy of } \\
\text { costs as the capacity is shared by passenger cars and } \\
\text { trucks. }\end{array}$ & Not in full \\
\hline Service frequency & $\begin{array}{l}\text { Indirectly in UNCTAD's LSCI } \\
\text { (as number of services) and } \\
\text { Lam and Yap (2011). }\end{array}$ & $\begin{array}{l}\text { Relevant. A higher service frequency reduces the } \\
\text { waiting times for users and increases their transport } \\
\text { options and hence generalized transport costs. }\end{array}$ & Full \\
\hline Number of vessels on service & UNCTAD's LSCI & $\begin{array}{l}\text { Not relevant as long as service frequencies are } \\
\text { included. }\end{array}$ & Not in full \\
\hline $\begin{array}{l}\text { Number of liner services / directly } \\
\text { connected ports }\end{array}$ & Tang et al. (2011) & $\begin{array}{l}\text { The number of directly connected ports is relevant. } \\
\text { More destinations reduce generalized transport costs } \\
\text { for users. }\end{array}$ & Full \\
\hline Number of service providers & $\begin{array}{l}\text { UNCTAD's LSCl, Bang et al. } \\
\text { (2014). }\end{array}$ & $\begin{array}{l}\text { Relevant. The relevance of the number of service } \\
\text { providers relates to the benefits of competition. In } \\
\text { some markets (e.g., UK to Spain) road transport may } \\
\text { be a competitive alternative, in other markets (e.g., } \\
\text { the Channel crossing) rail may compete, but these } \\
\text { alternatives are never perfect competition. Two com- } \\
\text { peting service providers are perfect substitutes. Thus, } \\
\text { 'ceteris paribus' competing service providers lower } \\
\text { the prices of service providers. }\end{array}$ & Full \\
\hline Transit time & Jiang et al. (2015) & $\begin{array}{l}\text { Not straightforward. There is a trade off between tran- } \\
\text { sit times and tariffs. The only improvement of tran- } \\
\text { sit time without associated higher fuel expense is a } \\
\text { reduction in the number of intermediate stops, which } \\
\text { is included in the indicator developed in this paper. }\end{array}$ & Full \\
\hline Distance & & $\begin{array}{l}\text { Not straightforward. In a 'gravity model' approach, } \\
\text { it can be argued that connections to distant desti- } \\
\text { nations are less relevant that connections to close } \\
\text { destinations. However, in the case of RoRo, the RoRo } \\
\text { part is only one components of a door-to-door jour- } \\
\text { ney, so the ports cannot be treated as destinations (in } \\
\text { comparison, such an approach does make sense for } \\
\text { airports). }\end{array}$ & Full \\
\hline
\end{tabular}

This column is not complete, see Pitoski et al. (2015) for a detailed analysis. Bartholdi et al. (2014) is not included as they use the same components as LSCI 


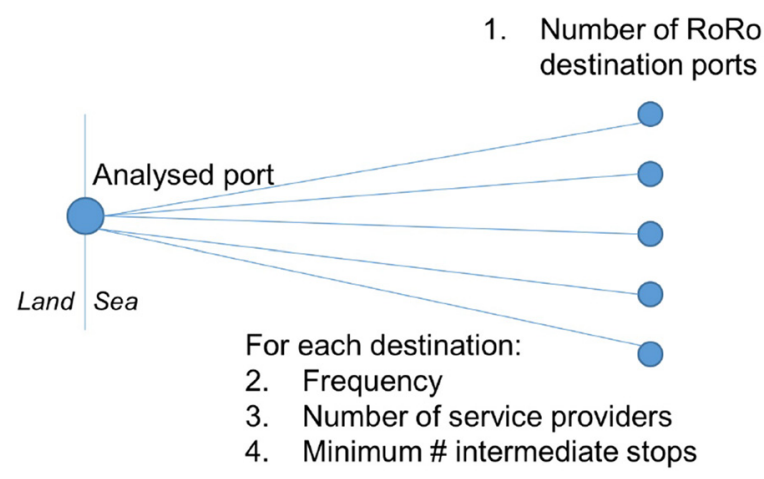

Fig. 1 The four components of RoRo connectivity

\section{The relative importance of the components}

Developing a method to calculate a connectivity score of a specific port based on the four variables depicted in Fig. 1 requires addressing the relative weights of the four components. As a reference, LSCI works with five components, each of which carry an equal weight. LSCI does not argue explicitly why weights are equal. Implicitly, this choice is based on the absence of hard empirical evidence regarding the appropriate weights of the components. Theoretically, the weight could be analyzed by taking the effect of these four components on the generalized transport costs of all port users. However, such an analysis has to our knowledge not been made, and certainly not specifically for RoRo. We propose a method where the connectivity of a port is the sum of the 'link qualities' of all its connections based on the 3 attributes of the links. To allow comparison over time and between ports we propose a method in which link qualities are positive and the maximum link quality is 1 . We measure the 'link quality' as the sum of three scores (between 0 and 1 ) for each of the link attributes. In this method (detailed below) the number of destinations carries more weight than the attributes of a link quality (frequency, number of service providers and minimum number of intermediate stops). This is intuitive, given that the number of destinations that can be reached is a key to the connectivity of a port. Note that this methodology explicitly allows for the development of connectivity indicators for different aggregation levels. Thus, the port-level connectivity can be extended to a region-level or country-level connectivity in a straightforward manner.

\section{Linear or diminishing returns.}

Diminishing marginal returns are present in a large array of natural and economic processes. Decades of research led to detailed descriptions of such relationships (Knight 1994; Le Galliard et al. 2003). Modeling approaches can be broadly divided into theoretical, based upon models stemming from the hypothesized relationships of individual components (Glomm and Ravikumar 1994); and empirical, based on fitting curves on actual data (Wilkinson 1984). We argue that for a number of the components included in our approach, the returns are diminishing. Table 2 shows our assessment of the theoretical basis for assuming diminishing returns of the three variables relevant to this study.

Based on Table 2, we propose to calculate a normalized score between 0 and 1 for each component, for each unique link (arrival-destination pair). The scores for frequency and number of service providers are based upon a positive relationship with diminishing 
Table 2 Assessment of the theoretical basis for assuming diminishing returns

\begin{tabular}{ll}
\hline Variable & Theoretical basis for diminishing returns? \\
\hline Frequency & $\begin{array}{l}\text { Yes. An additional service (increased frequency) has a } \\
\text { smaller effect on the average waiting times (assum- } \\
\text { ing random arrival) the larger the existing number of } \\
\text { services. } \\
\text { Yes. An additional service provider has a smaller effect } \\
\text { on the intensity of competition the larger the exist- } \\
\text { ing number of services. For most destinations, there } \\
\text { is only one service provider. The introduction of a } \\
\text { second service provider leads to competition on that } \\
\text { route, the effect of a third competitor is small. } \\
\text { No. An intermediate stop adds transit time. There is no } \\
\text { Minimum number of intermediate stops } \\
\text { reason to assume this effect will be less important the } \\
\text { larger the number of intermediate stops. }\end{array}$ \\
\hline
\end{tabular}

marginal returns and the score for the minimum number of intermediate stops is based upon a negative linear relationship.

We construct our score assigning a value of 1 to the maximum expected value of the relevant variable. For mathematical simplicity, we propose the use of a polynomic growth model (Foster 2004) to model the aforementioned non-linear relationship. Formally, let $Y_{i}$ be the normalized score for variable $i$. And let the indicator variable $i$ denote $i=1$ for the frequency component, $i=2$ for the number of service providers component, and $i=3$ for the minimum number of intermediate steps component. The normalized score for an arbitrary link $j$ is then defined by,

$$
\begin{aligned}
Y_{i, j} & =1-\left(1-x_{i, j} / a_{i}\right)^{b_{i}} \quad i=1,2 \\
Y_{3, j} & =1-\left(x_{3, j} / a_{3}\right)^{b_{3}}
\end{aligned}
$$

where $x_{i, j}$ is the realization of component $i$ for link $j$ (e.g., the weekly frequency of the Dover-Calais route operated by DFDS), $a_{i}$ represents the maximum theoretical value of the given variable, and $b_{i}$ is the curvature of the non-linear relationship. We estimate the maximum value of parameters $a_{1}-a_{3}$ through empirical argumentation based upon European data. In the absence of empirical data to determine the exact values for the curvature parameter $b_{i}$, we present a theoretical basis to define approximate parameters. In the Appendix, we explore the robustness of the final index with regards to the curvature (i.e., how sensitive the final connectivity indicator is to misspecifications of parameter $b_{i}$ ).

Parameter $a_{i}$ defines the value that at which the score for a value reaches its maximum value of 1 in the case of the frequency and service provider scores, or its minimum value of 0 in the case of the number of intermediate steps. We propose to set $a_{1}=168, a_{2}=5$, and $a_{3}=5$. Intuitively, the value $a_{1}=168$ corresponds to a maximum score for links with a frequency of 24 departures per day, 7 days a week. Our reasoning is that, in terms of RoRo cargo, any increase in the frequency of departures past this point exclusively affects the capacity of the link. While the connectivity of a port increases drastically when going from weekly to daily departures, there is no practical connectivity increase in going from hourly to half-hourly departures. We set the values of $a_{2}$ and $a_{3}$ based upon our empirical sample, such that the maximum score is equal to the $99^{\text {th }}$ percentile of the number of competitors per port and number of intermediate stops respectively ${ }^{9}$. 
To determine the curvature parameter for $b_{1}$ and $b_{2}$, we analyze the effect of an incremental increase in the variable of study. As an illustration, Fig. 2a shows the effect of the curvature parameter for the weekly frequency.

We hypothesize that the while both the number of service providers and the frequency of departures affect the connectivity of a port in a non-linear way, based on the argument presented above the latter particularly so. Thus, we define $b_{1}>b_{2}$. In particular, we propose to use $b_{1}=5$ and $b_{2}=4$ as an approximation of the behavior. With these values, the diminishing returns are clearly reflected in the scores, and the curve for higher frequencies is steeper than that of competing service. As an example, it takes three daily departures to achieve a score of $Y_{1}=0.5$, doubling the frequency to six daily departures results in $Y_{1}=0.76$. In the case of competing services, having only one service operating in the port results in $Y_{2}=0$, having two services results in $Y_{2}=0.59$, and increasing the number of competing services beyond four has marginal effect. The sensitivity analysis presented in the Appendix shows that while the parameter setting has an effect on the value of the index, the ranking as presented in this paper is relatively robust. However, we stress that our main theoretical contribution in this paper is to introduce a calculation method with diminishing returns, an in-depth analysis of the appropriate value is beyond the scope of this paper. Further work to empirically determine curvature parameter for different variables/links is a potential extension of the method presented in this paper. Since we argue that the relationship between the minimum number of intermediate stops is linear, we set $b_{3}=1$. This relationship is shown in Fig. $2 \mathrm{~b}$.

\section{Weights of link quality attributes}

We propose a method where the connectivity of a port is the sum of the 'link qualities' of all it's connections based on the 3 attributes of the links. To allow comparison over time and between ports we propose a method in which link qualities are positive and the maximum link quality is 1 . We measure the quality of a connection as the average of the three scores (between 0 and 1 ) for each of the individual factors. The method could potentially include a weight for each of the three scores. For instance, one could argue that frequencies are more relevant than the number of service providers, or the number of intermediate stops. However, in our method we do not assess weights to the three
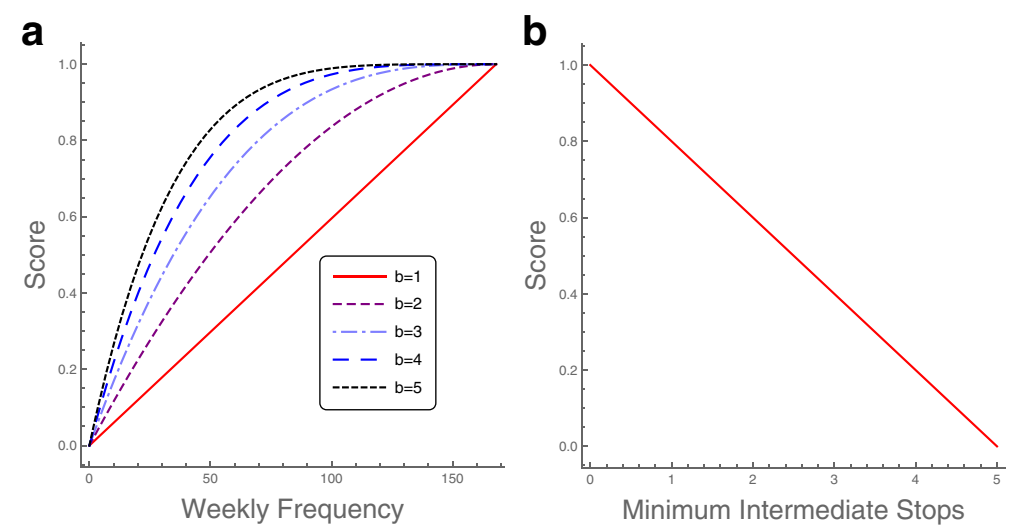

Fig. 2 Score calculation curves 
link attributes, as we have no theoretical or empirical basis for doing so. This is another potential next step in improving the RoRo connectivity indicator presented in this paper.

\section{Differentiation based on the importance of the destination ports}

Weights can be attributed to the destination ports. These weights can be based on distance, but as argued in Table 1, for RoRo shipping the shipping distance is not a good proxy for the distance to the final destinations of shipments. Therefore, we argue that attributing a lower weight to links over larger distances (as may be sensible from a 'gravity model' perspective) is not appropriate. Alternatively, the weight could be based on the importance (volume) of the destination port. However, in RoRo shipping, transshipment seldom occurs. The vast majority of shipments continues by road. Therefore, we argue against using the importance of the destination port to differentiate the weight of links. One could also argue that the access to consumers within a certain time period (say 6 hour drive) in the destination port could be a good variable to weight the links. However, we consider this as another next research step; in this paper we present a method without different weights to the destination ports. Formally, our approach can be presented in mathematical terms as follows:

$$
C_{p}=\sum_{j \in \mathcal{J}_{p}} \frac{1}{3}\left(Y_{1, j}+Y_{2, j}+Y_{3, j}\right),
$$

where $C_{p}$ is the connectivity indicator of port $p$ and $\mathcal{J}_{p}$ the set of links that connect port $p$ to its destinations.

\section{Empirical implementation: European RoRo shipping}

In this section, we apply the method outlined in the previous section to RoRo shipping in Europe. Europe is selected as RoRo is most advanced in Europe, with over 65 \% of the global fleet of RoRo deployed there (MDS Transmodal, 2013). In Europe, data is collected for all EU core ports that have RoRo services. These so-called 'core ports' have been identified by the European Union (European Commission, 2015) and handle the vast majority (well over $90 \%$ ) of all freight volumes handled in Europe. The detailed data required for the calculation of our RoRo connectivity index, however, is not centralized. Therefore, before applying the methodology, we describe our data collection strategy.

\section{Data collection}

The starting point of the data collection is the list of EU core ports that offer RoRo services (not all EU core ports have RoRo services). We define a RoRo service as a scheduled shipping service that individual transport companies can use with trucks. As explained in the motivation of this article, this definition explicitly excludes the shipping services offerd by car carriers, as these serve a completely different market: the transport of new vehicles for import and export. These car carriers generally do not provide short sea services, but focus on intercontinental services instead.

A majority of the RoRo services are used by passenger cars as well as trucks. For trucks, a number of services are provided for accompanied truck transport (the driver also stays onboard), while others are mostly provided for unaccompanied transport (the trailer is transported without the truck and driver). The selected time span for the collection of data on the RoRo services was mid-August (week 33 and 34) of 2015. This period is the 
high season for RoRo services, as some services partly aim at holiday-makers (for instance the service Portsmouth-Santander).

To construct our database, we collected the names of the service providers that serve European core ports. Following this, we downloaded the complete schedules for each of these service providers, thus including a number of non-core ports and a number of nonEU ports. Throughout this paper, we denote core EU ports in all tables in bold. From these schedules we extracted the departure/arrival times per destination as well as the distances, frequencies, and the number of intermediate ports. Given that a significant number of the schedules published by service providers do not specify routes, we used real-time geolocation of individual vessels through AIS (Automatic Identification System, accessed through http://www.marinetraffic.com) to calculate the specific routing of each schedule. Our final dataset contains schedules from 23 providers that altogether comprise 720 different services (routes) from/to 148 ports. Once this dataset was completed, we used two sources to calculate the distance between each pair of ports: the aforementioned AIS data and data obtained from http://www.vesseldistance.com, which determines the shortest distance based upon a specific waterway network. For robustness, we use the average of both measurements in our calculations. In the large majority of cases, both sources provide estimations within $5 \%$. Note that all the routes used in this paper comes from published schedules, but the detailed data comes from actual traffic data (i.e., the actual realization of the schedules). We exclude all unpublished (i.e., potential) indirect connections. For example, if a service provider offers the routes Barcelona-Savona, Barcelona-Tangier, and Tangier-Livorno but does not offer the route Barcelona-Livorno, we do not include the potential route of Barcelona-Tangier-Livorno. Similarly, we do not include potential connections using multiple providers. We show the complete list of ports and service providers in the Appendix. The resulting dataset is available from the authors upon request.

\section{Results}

Table 3 shows the summary statistics of the resulting dataset. This dataset comprises of 720 individual links (route/service-provider pair) that cover 620 unique routes.

We see that, as mentioned in the introduction, the vast majority of RoRo traffic is direct or with a very limited number of stops (75\% of the analyzed routes contain 1 stop or less, $95 \% 3$ or less). Also, the frequency of the connections is characterized by few, very

Table 3 Summary statistics

\begin{tabular}{|c|c|c|c|c|c|c|c|}
\hline & Mean & (Std. Dev) & Min & 1st quartile & Median & 3rd quartile & Max \\
\hline $\begin{array}{l}\text { Frequency of route } \\
\text { (departures/week) }\end{array}$ & 8.13 & (18.96) & 0.25 & 1 & 3 & 7 & 201 \\
\hline Distance (NM) & 600.20 & (590.73) & 10 & 154 & 394 & 810.5 & 2820 \\
\hline $\begin{array}{l}\text { Number of } \\
\text { intermediate stops } \\
\text { per route }\end{array}$ & 0.72 & $(1.17)$ & 0 & 0 & 0 & 1 & 7 \\
\hline $\begin{array}{l}\text { Number of service } \\
\text { providers per port }\end{array}$ & 1.62 & $(0.94)$ & 1 & 1 & 1 & 2 & 5 \\
\hline $\begin{array}{l}\text { Number of service } \\
\text { providers per route }\end{array}$ & 1.20 & $(0.47)$ & 1 & 1 & 1 & 1 & 3 \\
\hline $\begin{array}{l}\text { Unique number of } \\
\text { routes per port }\end{array}$ & 4.30 & $(3.83)$ & 1 & 1 & 3 & 6 & 19 \\
\hline
\end{tabular}


frequent connections that skew the distribution to the right. While the maximum frequency of any one given service is 201 departures a week (by two competing providers in the Dover-Calais route), the median frequency is only 3 departures a week. In terms of distance, we see a similar influence of a limited number of outliers. The largest distance (2820 NM, Bilbao-Rauma) is over 7 times the median.

Figure 3 shows the results of the connectivity index calculation as a heat map. A deeper red represents a larger connectivity indicator. Table 4 shows the resulting top 10 ranked ports. A complete ranking is reproduced in the Appendix.

Comparing the ranking of ports (Table 4) with the results overlaid in a map of Europe (Fig. 3), we can gather a number of insights. First, we see that none of the three most connected regions (North Sea, Baltic Sea, and Gulf of Finland) are driven by a single port, but by a number of ports (e.g., Zeebrugge-Antwerp-Rotterdam, Paldiski-Helsinki-St. Petersburg). This illustrates the usefulness of a connectivity indicator that can scale to arbitrary geographical regions. Furthermore, we observe the effect of the diminishing returns of link frequency. Comparing the two routes with the highest frequency, DoverCalais and Tallin-Helsinki, we see that even though the former's frequency is more than double (201 Vs. 87 departures per week), the latter appear significantly higher in the connectivity ranking. Helsinki is number 2 and Tallin 48, while Dover is number 56 and Calais 94. This important difference in connectivity is due to the significant difference in number of connections (Dover is connected with 2 ports, while Helsinki with 17). Additionally,

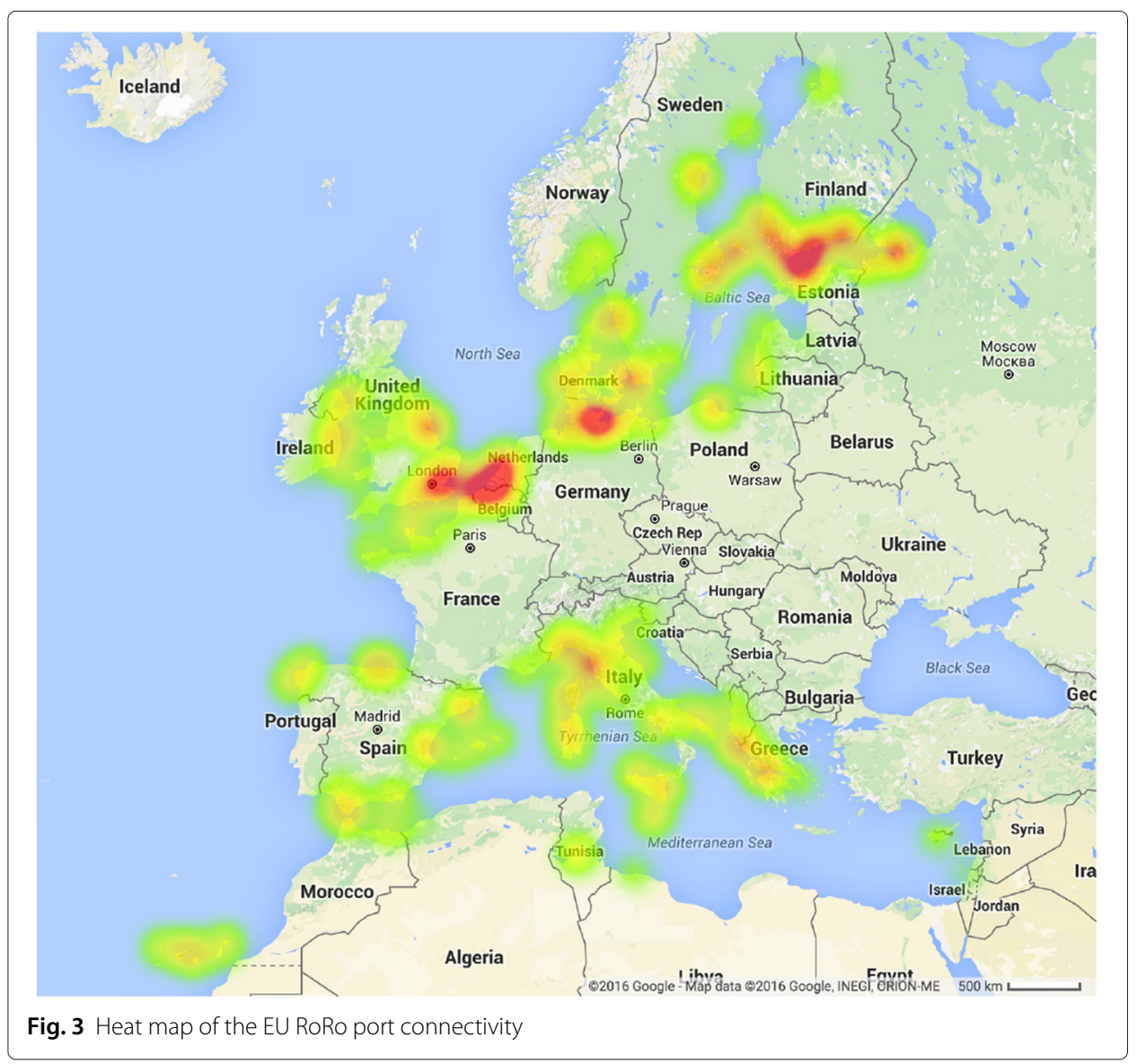


Table 4 Port ranking

\begin{tabular}{ll}
\hline Port & $C_{p}$ \\
\hline Zeebrugge & 6.18 \\
Helsinki & 5.68 \\
Lubeck & 5.22 \\
St. Petersburg & 4.96 \\
HaminaKotka & 4.74 \\
Rotterdam & 4.67 \\
Patras & 4.26 \\
Livorno & 4.26 \\
Antwerp & 4.24 \\
Tilbury & 4.18 \\
\hline
\end{tabular}

Bold typeface denotes core ports

the Helsinki-Tallin link ranks higher than the Dover-Calais link due to the number of competing service providers in our database (3 Vs. 2).

To further characterize the top-ranked ports, we show the port throughput in 2014 in Table 5. We show RoRo and container volume (in 1000 Tons) as well as the ratio of RoRo to container traffic per port. We see that the majority of top ranked ports derive a substantial proportion of their throughput from RoRo traffic. The exceptions are Antwerp, Rotterdam, HaminaKotka, and St Petersburg. Antwerp and Rotterdam have a considerable RoRo throughput in absolute terms but they are very large container ports. In the case of HaminaKotka and St Petersburg, their absolute RoRo is significantly smaller than the rest of the top ranked ports. HaminaKotka in particular, derives a large part of its business from forestry industry exports that is stowable RoRo (Sto-Ro) and thus not considered RoRo by our definition. These services, however, are open to other businesses, making the potential connectivity of this port particularly high. Finally, we see that only 1 of the top ports is a dedicated RoRo port (Patras). 8 out of the top 10 ports ave a RoRo throughput superior to 1.000 .000 Tons a year.

Table 5 Throughput of top connected ports year 2014 (in 1000 Ton)

\begin{tabular}{llll}
\hline & RoRo volume & Container volume & Ratio \\
\hline ZEEBRUGGE & 13000 & 20000 & 0.65 \\
HELSINKI & 6434 & 3253 & 1.98 \\
LUBECK $^{a}$ & 13629 & 1798 & 7.58 \\
ST PETERSBURG & 846 & 23818 & 0.04 \\
HAMINAKOTKA & 365 & 4809 & 0.08 \\
ROTTERDAM $^{\text {PATRAS }}{ }^{a}$ & 20005 & 127598 & 0.16 \\
LIVORNO $^{\text {ANTWERP }}$ & 2640 & - & \\
ANTWE $^{\text {TILBURY }}{ }^{a}$ & 10795 & 6694 & 1.61 \\
Average & 4479 & 108317 & 0.04 \\
Median & 7842 & 9081 & 0.86 \\
Total & 8003 & 33930 & 1.44 \\
\hline Source & 7138 & 9081 & 0.65
\end{tabular}

Source: Self-reported port statistics except ${ }^{a}$, source: Eurostat

Bold typeface denotes core ports 


\section{Conclusions}

In this paper we have presented a calculation method for a RoRo connectivity indicator and an application to Europe, the largest RoRo market worldwide. A RoRo connectivity indicator is relevant for policy-makers, port users, port authorities and RoRo service providers, as it provides insights in the relative connectivity of various RoRo ports, and more importantly, of the evolution of RoRo connectivity over time. This paper is, to our knowledge, the first paper that develops a RoRo connectivity indicator. The following main conclusions can be drawn from this paper.

First, RoRo connectivity indicator is similar to previously developed indicators dealing with maritime container connectivity. Nevertheless, there are also differences: contrary to container services that generally include transshipment in intermediate ports, RoRo services are generally direct services. This is partly due to the time sensitive nature of RoRo cargoes. In addition, for RoRo services, the capacity is shared between passenger cars and freight trucks. For these reasons, the relevant components of a RoRo connectivity indicator differ from those of a container connectivity indicator, and consists of: the number of directly served destinations, the number of service providers, the frequencies and the number of intermediate stops.

Second, in this paper we have introduced the notion of diminishing returns to the components of connectivity. While the most widely used indicator on maritime container connectivity (LSCI) is based on constant returns, we argue that for frequencies and number of service providers, using diminishing returns is more appropriate.

Third, our application of the method to European ports show that Zeebrugge is the best connected EU core port. This is due to its connections with the UK as well as Scandinavia and Southern European ports. However, as previously argued, the comparative connectivity, albeit relevant, is in our view less relevant than the analysis of the evolution of connectivity over time. The latter requires repeating this method in the coming years.

Fourth, we show that the connection Helsinki-Tallinn has the highest link quality. This is due to the high frequency (even though with 87 weekly services this is lower than DoverCalais with 201) and the high number of competing service providers (four compared to two on the route Dover-Calais - the route with the third highest route quality, the second being Dublin-Holyhead). This illustrates the effect of the diminishing returns to scale on link qualities: the large number of extra services Dover-Calais carry less weight than the difference in the number of service providers. As indicated in the method, we regard research to provide a basis for allocating weights to the components of link quality an avenue for further research.

Fifth, this first paper on the connectivity of RoRo ports points to at least five potential steps for further research: empirical analysis on the weight of the various components of a connectivity indicator; empirical research on the shape of a curve that reflects the diminishing returns to additional frequency or services providers; research to expand the current index, currently limited to maritime connections, to an index that incorporates port and hinterland features such as population within a 24 hour radius from the port or congestion; research to analyze whether or not RoRo connectivity influences such variables as RoRo volumes and bilateral trade, and its relation to container connectivity; and research to assess the theoretical connectivity ranking with actual traffic patterns.

It's important to note that our empirical study has a number of limitations. Given that we only use published schedule data, certain routes may be under- or over-represented 
in our database, either by outdated/erroneous published data or by the omission of unpublished routes. As suggested above, however, tracking the RoRo connectivity indicator in time will enable richer insights, of which the ones put forward in this paper are a first step.

\section{Endnotes}

${ }^{1}$ Connectivity indicators have also been developed for airline networks, see Arvis and Shepherd (2011). One leading logistics service provider, DHL, also eveloped a more encompassing indicator of connectedness (Ghemawat ASP 2012).

${ }^{2}$ Connectivity is sometimes used more loosely for a port's maritime and hinterland accessibility (European Commission 2015b). We argue that this misses the role of scheduled services as central characteristic of connectivity; ports with excellent infrastructure and draft but without scheduled services do not provide connectivity to (potential) port users.

${ }^{3}$ We note that there are also RoRo/LoLo vessels. These carry both containers and cargo on wheels. Wherever they are operated in fixed schedules and can be used by individual trucks they are included in the analysis.

${ }^{4}$ Distance is included in the well-established World Bank's Air Connectivity Index, as an impedance to movement (Arvis and Shepherd 2011).

${ }^{5}$ Transit time is not included as faster transit times incur higher costs. We assume that all operators have the most attractive proposition in terms of transit time and costs.

${ }^{6}$ Frequencies are partly determined by the choice of the capacity of ship's deployed on routes. In theory, an operator could deploy a very small vessel, enabling a high frequency without reducing generalised transport costs. However, in practice, large ships are deployed on routes with high frequencies as well (e.g. Dover - Calais). Thus, we argue that frequency is an appropriate component of a RoRo connectivity indicator.

${ }^{7}$ We acknowledge that the number of service providers is not a complete indicator for the intensity of competition. For instance, RoRo services can also compete with train links (mostly relevant for the Channel Tunnel) and a RoRo service can compete with another RoRo service to a nearby port (the competition between the routes Dover-Calais and Dover-Dunkerque is a good example). However, developing a complete indicator of competition intensity on a RoRo route is beyond the scope of this paper; including the number of service providers is in our view a valid proxy.

${ }^{8}$ The minimum refers to situations where one service provider may offer a service Hamburg-Helsinki-St Petersburg, while another operator offers a direct service Hamburg-StPetersburg. In this case the value would be nil.

${ }^{9}$ Note that it is theoretically possible to update the values of the maximum scores in successive studies. However, we argue against it for the RoRo indicator given that: (a) fixed scores allow for the comparison of different datasets; (b) there is no theoretical reason to hypothesize that the influence of the relevant components is dynamic in nature (e.g., the point at which diminishing returns starts to have an impact on the effect of adding an additional competitor is robust in time).

\section{Appendix}

In Table 6 we show list of all ports included in this study, ranked according to the connectivity indicator. 
Table 6 Complete ranking of ports

\begin{tabular}{|c|c|c|c|c|c|}
\hline ZEEBRUGGE & 6.18 & SWINOUJSCIE & 1.52 & TRIESTE & 0.74 \\
\hline HELSINKI & 5.68 & ANCONA & 1.51 & VENTSPILS & 0.74 \\
\hline LUBECK & 5.22 & DOVER & 1.51 & GHENT & 0.73 \\
\hline ST PETERSBURG & 4.96 & ALMERIA & 1.49 & PORTO TORRES & 0.71 \\
\hline HAMINA-KOTKA & 4.74 & BARI & 1.49 & LIEPAJA & 0.70 \\
\hline ROTTERDAM & 4.67 & ROSSLARE & 1.49 & LIMASSOL & 0.69 \\
\hline LIVORNO & 4.26 & BELFAST & 1.48 & TANGIER & 0.69 \\
\hline PATRAS & 4.26 & LAS PALMAS DE GRAN CANARIA & 1.47 & DUNKERQUE & 0.65 \\
\hline ANTWERP & 4.24 & BRINDISI & 1.45 & UUSIKAUPUNKI & 0.64 \\
\hline TILBURY & 4.18 & OSLO & 1.45 & VENEZIA & 0.64 \\
\hline PALDISKI & 4.10 & CUXHAVEN & 1.43 & LAVRIO & 0.62 \\
\hline GOTHENBURG & 3.57 & CIVITAVECCHIA & 1.42 & PUERTO DEL ROSARIO & 0.62 \\
\hline HANKO & 3.46 & KIEL & 1.41 & SEVILLA & 0.62 \\
\hline STOCKHOLM & 3.44 & CORFU & 1.35 & TRIPOLI/AL KHOMS & 0.62 \\
\hline TURKU & 3.43 & LANGNAS & 1.30 & LARNE & 0.60 \\
\hline DUBLIN & 3.21 & LONDON & 1.26 & NICE & 0.54 \\
\hline CORSICA & 3.10 & BREMERHAVEN & 1.25 & CEUTA & 0.53 \\
\hline IGOUMENITSA & 3.08 & BILBAO & 1.23 & TOULON & 0.53 \\
\hline BARCELONA & 2.97 & AARHUS & 1.21 & DIEPPE & 0.50 \\
\hline MARIEHAMN & 2.95 & SAVONA & 1.21 & ELBA & 0.50 \\
\hline VALENCIA & 2.77 & CAIRNRYAN & 1.18 & NEWHAVEN & 0.50 \\
\hline HULL & 2.76 & ARRECIFE & 1.17 & TANGER-MED & 0.50 \\
\hline TRAVEMUNDE & 2.72 & DURRES & 1.17 & CAEN & 0.49 \\
\hline CATANIA & 2.51 & PALMA DE MALLORCA & 1.13 & MALMO & 0.48 \\
\hline GENOVA & 2.48 & ROSCOFF & 1.13 & FELIXTOWE & 0.46 \\
\hline GDYNIA & 2.41 & CADIZ & 1.12 & KARLSKRONA & 0.46 \\
\hline TRELLEBORG & 2.41 & NYNASHAMN & 1.11 & FISHGUARD & 0.45 \\
\hline ROSTOCK & 2.38 & SANTA CRUZ DE LA PALMA & 1.06 & NAANTALI & 0.45 \\
\hline UST-LUGA & 2.31 & BREVIK & 1.05 & PEMBROKE & 0.45 \\
\hline SARDINIA & 2.28 & ALGECIRAS & 1.03 & GRENAA & 0.44 \\
\hline COPENHAGEN & 2.24 & CAGLIARI & 1.03 & HEYSHAM & 0.44 \\
\hline SALERNO & 2.24 & MAHON & 1.00 & VARBERG & 0.44 \\
\hline RAUMA & 2.20 & EL FERROL & 0.97 & LE HAVRE & 0.41 \\
\hline IMMINGHAM & 2.17 & HOLMSUND & 0.97 & MALAGA & 0.40 \\
\hline ESBJERG & 2.08 & HUSUM & 0.97 & NADOR & 0.40 \\
\hline HARWICH & 2.05 & OULU & 0.97 & NEWCASTLE & 0.40 \\
\hline PALERMO & 2.04 & SUNDSVALL & 0.97 & POOLE & 0.40 \\
\hline PORTSMOUTH & 2.02 & LIVERPOOL & 0.95 & SASSNITZ & 0.40 \\
\hline MALTA & 2.00 & FREDERIKSHAVN & 0.92 & ST MALO & 0.40 \\
\hline SANTA CRUZ DE TENERIFE & 1.90 & PIOMBINO & 0.90 & GDANSK & 0.37 \\
\hline KLAIPEDA & 1.89 & CALAIS & 0.86 & RIGA & 0.37 \\
\hline KILLINGHOLME & 1.87 & FREDERICIA & 0.86 & MARSEILLE & 0.36 \\
\hline AMSTERDAM & 1.80 & HOEK VAN HOLLAND & 0.85 & ROSYTH & 0.36 \\
\hline LEIXOES & 1.76 & HOLYHEAD & 0.84 & GHAZAOUET & 0.35 \\
\hline TUNIS & 1.72 & MELILLA & 0.79 & CORK & 0.34 \\
\hline SANTANDER & 1.70 & YSTAD & 0.78 & HAIFA & 0.34 \\
\hline CHERBOURG & 1.69 & PLYMOUTH & 0.76 & IGGESUND & 0.34 \\
\hline TALLINN & 1.68 & IBIZA & 0.75 & ORAN & 0.34 \\
\hline RAVENNA & 1.58 & KARLSHAMN & 0.75 & & \\
\hline KAPELLSKAR & 1.56 & TEESPORT & 0.75 & & \\
\hline
\end{tabular}

Bold typeface denotes core ports 
Table 7 Service Providers used in this study

\begin{tabular}{|c|c|c|}
\hline ADRIA FERRIES S.p.A. ANCONA & GRIMALDI COMPAGNIA DI NAVIGAZIONE SPA PALERMO & TRANSATLANTIC GOTHENBURG \\
\hline ANEK LINES CHANIA & IRISH FERRIES LTD DUBLIN & TRANSFENNICA NEDERLAND B.V. AMSTERDAM \\
\hline BRITTANY FERRIES LTD DEVON & MANN \& SON (LONDON) LTD - HARWICH & TRASMEDITERRANEA MADRID \\
\hline CLdN ro-ro SA LUXEMBOURG & MOBY LINES EUROPE GMBH WIESBADEN & AS TALLINK GRUPP TALLINN \\
\hline CORSICA FERRIES BASTIA & P\&O SHORT SEA FERRIES LTD DOVER & TT-LINE GMBH \& CO. KG TRAVEMUNDE \\
\hline DFDS A/S COPENHAGEN & POLSKA ZEGLUGA BALTYCKA SA KOLOBRZEG (POLFERRIES) & UNITY LINE LIMITED SP. Z O.O. SZCZECIN \\
\hline ECKERO LINE AB OY HELSINKI & SALAMIS TOURS (HOLDINGS) PUBLIC LTD LEMESOS & VIKING LINE ABP MARIEHAMN \\
\hline FINNLINES PLC HELSINKI & STENA LINE GOTHENBURG & \\
\hline
\end{tabular}


Table 8 Sensitivity analysis of the curvature parameters $b_{1}$ and $b_{2}$

\begin{tabular}{|c|c|c|c|c|c|c|c|c|c|c|}
\hline Port & $b_{1}=5, b_{2}=4$ & $b_{1}=2, b_{2}=4$ & $b_{1}=10, b_{2}=4$ & $b_{1}=5, b_{2}=2$ & $b_{1}=5, b_{2}=8$ & $b_{1}=2, b_{2}=2$ & $b_{1}=2, b_{2}=8$ & $b_{1}=10, b_{2}=2$ & $b_{1}=10, b_{2}=8$ & $b_{1}=b_{2}=b_{3}=1$ \\
\hline ZEEBRUGGE & 1 & 1 & 1 & 1 & 1 & 1 & 1 & 1 & 1 & 1 \\
\hline HELSINKI & 2 & 2 & 2 & 2 & 2 & 2 & 2 & 2 & 2 & 2 \\
\hline LUBECK & 3 & 2 & 3 & 3 & 3 & 3 & 3 & 3 & 3 & 3 \\
\hline ST PETERSBURG & 4 & 4 & 4 & 4 & 4 & 4 & 4 & 5 & 4 & 4 \\
\hline HAMINAKOTKA & 5 & 5 & 6 & 6 & 5 & 5 & 5 & 6 & 5 & 5 \\
\hline ROTTERDAM & 6 & 6 & 5 & 5 & 6 & 6 & 6 & 4 & 6 & 6 \\
\hline PATRAS & 7 & 9 & 7 & 7 & 8 & 9 & 9 & 7 & 7 & 9 \\
\hline LIVORNO & 8 & 10 & 8 & 8 & 9 & - & 10 & 8 & 8 & - \\
\hline ANTWERP & 9 & 7 & 9 & - & 7 & 8 & 7 & - & 9 & 10 \\
\hline TILBURY & 10 & 8 & 10 & 10 & 10 & 10 & 8 & 10 & 10 & 8 \\
\hline
\end{tabular}

Bold typeface denotes core ports 
Table 9 Ports ranked by number of links

PALDISKI
ZEEBRUGGE
ST PETERSBURG
HELSINKI
LUBECK
HAMINAKOTKA
ROTTERDAM
TILBURY
PATRAS
LIVORNO

Table 7 shows a list of all the service providers analyzed in this study. The data added to our database includes the complete schedule published by every provider at the time of analysis.

Table 8 shows a summary of the sensitivity experiments carried out for the curvature parameters $b_{1}$ and $b_{2}$. Column 2 shows the ranking under the base conditions used in our empirical study. Columns 3 to 10 show the ranking of each of the Top 10 ports in the base case according to the new experimental set up (detailed in row 1). We use a full factorial experimental design with high values of $b_{1}=10 ; b_{2}=8$ and low values of $b_{1}=2 ; b_{2}=2$. For completeness, we also investigate the influence of the curvature parameters by presenting an alternative 'linear' ranking (with $b_{1}=b_{2}=b_{3}=1$ ). Table 8 shows that the highest positions of the ranking are robust to the curvature parameter. The curvature has a limited effect in the bottom half of the ranking. Note that in experiments 4, 6, and 8 Antwerp/Livorno drop out from the top 10. In these cases they are replaced by Paldiski.

This shows that in terms of connectivity, Antwerp Livorno, and Paldiski are comparable but driven by different factors. These ports have a large number of connections, however Antwerp and Paldiski have relatively infrequent connections offered by a large number of providers (high competition) while Livorno offers very frequent connections, but each dominated by a single player. To better understand the influence of the different components, we specify the top 10 ranking of ports according exclusively to the number of links in Table 9. We see that the number of links, while important, does not dominate the final connectivity indicator.

Competing interests

The authors declare that they have no competing interests.

Authors' contributions

$\mathrm{PdL}$ and JF developed the research design, PdL, MU and RH did the data collection and the development of the calculation method, together with K. Pitoski, who they thank for his contribution, K. Pitoski indicated he does not want to be listed as co-author. MU developed the calculations. All authors contributed to the writing of the paper. All authors read and approved the final manuscript.

Author details

${ }^{1}$ School of Industrial Engineering, Eindhoven University of Technology, Eindhoven, Netherlands. ${ }^{2}$ Centre for Maritime

Studies, University of Turku, Turku, Finland.

Received: 4 February 2016 Accepted: 8 June 2016

Published online: 20 July 2016 


\section{References}

Arvis J, Shepherd B (2011) The air connectivity index: measuring integration in the global air transport network. In: World Bank Policy Research Working Paper Series. World Bank, Washington D.C. Vol. 5722

Arvis J-F, Duval Y, Shepherd B, Utoktham C (2013) Trade costs in the developing world: 1995-2010. In: World Bank Policy Research Working Paper Series. World Bank, Washington D.C. Vol. 6309

Bang JK, Greve M, Westergaard-Kabelmann T (2014) A leading trade nation: The role of container shipping and logistics in enhancing trade and economic growth in China. Technical report, Maersk Group

Bartholdi J, Jarumaneeroj P, Ramudhin A (2014) A new connectivity index for container ports. Working Paper (for publication). http://www.gatech.pa/docs/publications/en/GTP-WP/GTP-WP-A-New-Connectiviy-Index-forContainer-Ports.pdf

de Langen P, Nidjam M, van der Horst M (2007) New indicators to measure port performance. J Maritime Res 4(1):23-36

De Langen PW, Van Meijeren J, Tavasszy LA (2012) Combining models and commodity chain research for making long-term projections of port throughput: An application to the hamburg-le havre range. Eur J Transp Infrastruct Res (EJTIR) 12(3):2012

European Commission (2014) Motorways of the sea. Technical report. http://ec.europa.eu/transport/modes/maritime/ motorways_sea/index_en.htm, a

European Commission (2015a) List of sea ports in the core and comprehensive network. Technical report. http://ec europa.eu/transport/modes/maritime/ports/doc/2014_list_of_329_ports_june.pdf, b

European Commission (2015b) Ports; an engine for growth, where we are headed one year on. Technical report. http:// ec.europa.eu/transport/modes/maritime/ports/doc/2014-ports-leaflet.pdf, accessed 18th of December 2015, c

European Sea Ports Organization (2010) Port performance indicators - selection and measurement. Technical report. http://pprism.espo.be/ProjectOverview.aspx

Eurostat (2015) Maritime transport statistics. Technical report. http://appsso.eurostat.ec.europa.eu/nui/show.do?dataset= mar_sg_am_cwk\&lang=en

Foster KR (2004) Diminishing returns in social evolution: the not-so-tragic commons. J Evol Biol 17(5):1058-1072

Ghemawat ASP (2012) DHL Global Connectedness Index 2012: Analysing global flows and their power to increase prosperity. DHL, http://www.dhl.com/content/dam/flash/g0/gci_2012/download/dhl_gci_2012_complete_study. pdf. Accessed 23 March 2014

Glomm G, Ravikumar B (1994) Public investment in infrastructure in a simple growth model. J Econ Dynamics Control 18(6):1173-1187

Jiang J, Lee LH, Chew EP, Gan CC (2015) Port connectivity study: An analysis framework from a global container liner shipping network perspective. Transp Res Part E: Logist Transp Rev 73:47-64

Knight FH (1994) Diminishing returns from investment. J Polit Econ 1944:26-47

Lam JSL, Yap WY (2011) Dynamics of liner shipping network and port connectivity in supply chain systems: analysis on east asia. J Transport Geogr 19(6):1272-1281

Le Galliard JF, Ferrière R, Dieckmann U (2003) The adaptive dynamics of altruism in spatially heterogeneous populations. Evolution 57(1):1-17

Lloyd's List Intelligence (2009) Measuring global seaborne trade. Technical report. http://www.imsfinfo/papers/ NewOrleans2009/Wally_Mandryk_LMIU_IMSF09.pdf. International Maritime Statistics Forum. New Orleans

MDS Transmodal (2013) Roro market report. Technical report. Available at http://www.mdst.co.uk/attachments/ downloads/210034_presentation_7.pdf. Accessed 18th December 2015

Pitoski K, de Langen P, Udenio M, Fransoo J (2015) A review of connectivity measures in maritime transport. Beta Working Paper. Eindhoven University of Technology

Port of Antwerp (2014) Connectivity platform. Technical report. http://www.portofantwerp.com/en/connectivity. Accessed 10th February 2015

Tang LC, Low JM, Lam SW (2011) Understanding port choice behavior-a network perspective. Netw Spatial Econ 11(1):65-82

UNCTAD (2014) Statistics liner shipping connectivity index. Technical report. http://unctadstat.unctad.org/wds/ TableViewer/tableView.aspx?Reportld=92. Accessed 11th March 2014

Wang Y, Cullinane K (2008) Measuring container port accessibility: An application of the principal eigenvector method (pem). Marit Econ Logist 10(1):75-89

Wilkinson GS (1984) Reciprocal food sharing in the vampire bat. Nature 308(5955):181-184

Wilmsmeier G, Hoffmann J (2008) Liner shipping connectivity and port infrastructure as determinants of freight rates in the caribbean. Maritime Econ Logist 10(1):130-151

Wilmsmeier G, Notteboom T (2011) Determinants of liner shippping network configuration: a two-region comparison. GeoJournal 76(3):213-228 